\title{
A study that shows the existence of a simple relationship among square, circle, Golden Ratio and arbelos of Archimedes and from which to identify the real Pi value (Mother Goddess Kaali Maata Unified method)
}

\section{R. D. Sarva Jagannadha Reddy}

Abstract: This study unifies square, circle, Golden Ratio, arbelos of Archimedes and $\pi$ value. The final result, in this unification process, the real $\pi$ value is identified, and is, $\frac{14-\sqrt{2}}{4}=3.14644660942 \ldots$

Key words: Arbelos, area, circle, diameter, diagonal, Golden Ratio, Perimeter, $\pi$ value, side, square

\section{Introduction}

The geometrical entitles and concepts such as circle, square, triangle, Golden Ratio have been studied extensively. "The Golden Ratio is the ratio of two line segments ' $a$ ' and ' $b$ ' (when $a<b)$ such that $\frac{a}{b}=\frac{b}{a+b}$. The ratio $\phi=\frac{\mathrm{a}}{\mathrm{b}}=\frac{\sqrt{5}-1}{2} \approx 0.6180339887498948482045868343656$, while the reciprocal $\frac{\mathrm{b}}{\mathrm{a}}=\frac{\sqrt{5}+1}{2}=$ 1.6180339887498948482045868343656. Notice the relationship between the decimals. It suggests that $\phi+1=\frac{1}{\phi} \%$ (A.S. Posamentier and I. Lehmann, 2004, $\pi$ : A Biography of the World's Most Mysterious Number, Page 146).

Archimedes (240 BC) of Syracuse, Greece, called the area arbelos that is inside the larger semi circle, but outside the two smaller semi circles of different diameters. By its shape it is also called as "a shoemaker's knife".

The Golden Ratio and the arbelos of Archimedes are different concepts. But in this paper by the grace of God, it has become possible to see that these two concepts too have an interesting and unexpected inter relationship between each other (one). Further, this relationship has an extended relationship also with the circle (two). It is a well known fact that there exists simple and understable relationship between circle and square (three). As circle, square are related, their combined interrelationship has been extended to $\pi$ value also (four).

There is, thus, a divine chain of bond (of four interconnecting relations) exists, among square, circle, Golden Ratio, arbelos and $\pi$ value. (Here $\pi$ value means a true/ real/ exact/ line-segment based value. The stress here, on the adjectives to $\pi$, has become necessary, because $3.14159265358 \ldots$ of Polygon is attributed or thrust on circle. In other words, this number to circle is a borrowed number from polygon and its existence thus can not be seen in the radius of the circle, naturally. However, the new $\pi$ value $\frac{14-\sqrt{2}}{4}=$ $3.14644660942 \ldots$ (unlike with official $\pi$ value $3.14159265358 \ldots$ ) is inseparable with radius and is, here, humbly submitted to the World of Mathematics:

Area of the circle

$$
=r\left(\frac{7 r}{2}-\frac{\sqrt{2} r}{4}\right)=\pi r^{2}
$$

Circumference of the circle

$$
=6 r+\frac{2 r-\sqrt{2} r}{2}=2 \pi r
$$

In support of the above formulae, this paper also chooses and confirms that the real $\pi$ value is $\frac{14-\sqrt{2}}{4}=$ $3.14644660942 \ldots$ 


\section{Procedure}

1. Draw a square $\mathrm{ABCD}$. Draw two diagonals. Inscribe a circle with centre ' $\mathrm{O}$ ' and with radius $\frac{1}{2}$, equal to half of the side $\mathrm{AB}$ of the square, whose length is 1 .

$\mathrm{AB}=$ Side $=\mathrm{EN}=$ diameter $=1$

$\mathrm{AC}=\mathrm{BD}=$ Diagonal $=\sqrt{2}$

2. $\quad \mathrm{E}$ is the mid point of $\mathrm{AD}$

$\mathrm{AE}=\frac{1}{2}, \quad \mathrm{AB}=1$

Triangle EAB, $\quad \mathrm{EB}=$ hypotenuse $=\sqrt{\frac{5}{4}}$

$\mathrm{EH}=\frac{1}{2}$

$\mathrm{HB}=\mathrm{EB}-\mathrm{EH}=\sqrt{\frac{5}{4}}-\frac{1}{2}=\frac{\sqrt{5}-1}{2}$

Golden Ratio $=\mathbf{H B}=\frac{\sqrt{5}-1}{2}$

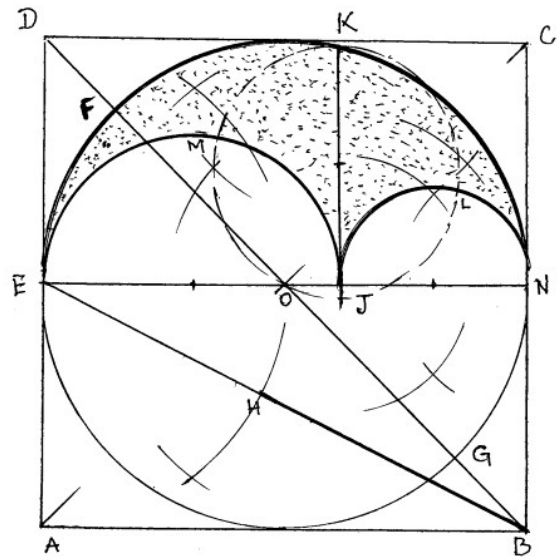

3. $\quad \mathrm{EN}=$ Diameter $=1$

$\mathrm{EJ}=\mathrm{HB}=\frac{\sqrt{5}-1}{2}=0.61803398874 \ldots$

$\mathrm{JN}=\mathrm{EN}-\mathrm{EJ}=1-\left(\frac{\sqrt{5}-1}{2}\right)=\frac{3-\sqrt{5}}{2}=0.38196601126 \ldots$

4. Draw two semicircles on EN. And one semicircle with EJ as its diameter, and second semicircle with $\mathrm{JN}$ as its diameter.

5. So, the diameter of the EJ semicircle $=$ Golden Ratio $=\frac{\sqrt{5}-1}{2}$ and

the diameter of the $\mathrm{JN}$ semicircle $=\frac{3-\sqrt{5}}{2}$

6. The area present (which is shaded) outside the two semicircles (of EJ and JN) and within the larger EN semi circle, is called arbelos of Archimedes.

7. Draw a perpendicular line on $\mathrm{EN}$ at $\mathrm{J}$ which meets circumference at $\mathrm{K}$.

$\mathrm{KJ}=\sqrt{\mathrm{EJ} \times \mathrm{JN}}$ (this is Altitude Theorem)

$=\sqrt{\frac{\sqrt{5}-1}{2} \times \frac{3-\sqrt{5}}{2}}=\sqrt{\sqrt{5}-2}=0.48586827174$ 
8. Draw a full circle with diameter KJ. It has already been established that this area of the full circle is equal to the area of the shaded region called arbelos.

9. To calculate the area of the arbelos we have the following formulas.

$\frac{\pi \mathrm{q}(\mathrm{d}-\mathrm{q})}{4}$ and $\pi\left[\frac{\mathrm{h}}{2}\right]^{2}$

where $\mathrm{h}=$ perpendicular line $\mathrm{KJ}=\sqrt{\sqrt{5}-2}=$ diameter of the circle LKM

$\frac{\mathrm{h}}{2}=$ radius of LKM circle.

10. Now, let us see the first formula

$\frac{\pi \mathrm{q}(\mathrm{d}-\mathrm{q})}{4}$

$\mathrm{q}=\mathrm{JN}=\frac{3-\sqrt{5}}{2}$

$\mathrm{d}=\mathrm{EN}=$ diameter $=1$

$=\frac{\pi\left(\frac{3-\sqrt{5}}{2}\right)\left\{1-\left(\frac{3-\sqrt{5}}{2}\right)\right\}}{4}=\left(\frac{\pi}{4}\right)(\sqrt{5}-2)$

$=\left(\frac{\pi}{4}\right) \times 0.23606797749$

11. The conventional formula is $\pi \mathrm{r}^{2}$.

$\mathrm{KJ}=$ diameter $=\mathrm{h}=\sqrt{\sqrt{5}-2}$

Radius $=\frac{\text { diameter }}{2}=\frac{\mathrm{h}}{2}=\frac{\sqrt{\sqrt{5}-2}}{2}=0.24293413587$

$\pi \times 0.24293413587 \times 0.24293413587=\pi \times 0.05901699437$

\section{Part-II}

12. $\pi$ value is known and hence, it is possible to find out the area of the arbelos either from $\frac{\pi \mathrm{q}(\mathrm{d}-\mathrm{q})}{4}$ or $\pi\left(\frac{\mathrm{h}}{2}\right)^{2}$

13. As there are two $\pi$ values now $3.14159265358 \ldots$ and $3.14644660942=\frac{14-\sqrt{2}}{4}$, the time has come, to find a way to decide which number actually represents $\pi$ value.

14. The following formula helps in deciding the real $\pi$ value. The formula is

Side $=\mathrm{a}=$ diameter $=\mathrm{d}=1$

Diagonal $=\sqrt{2} \mathrm{a}=\sqrt{2}$

Perimeter of the square

Half of 7 times of side of square $-\frac{1}{4}$ th of diagonal

$=\frac{4 a}{\frac{7 a}{2}-\frac{\sqrt{2} a}{4}}=\frac{4}{\frac{7}{2}-\frac{\sqrt{2}}{4}}=\frac{4}{\frac{14-\sqrt{2}}{4}}=\frac{16}{14-\sqrt{2}}$ 
A study that shows the existence of a simple relationship among square, circle, Golden Ratio .....

(when a circle is inscribed in a square, or when a square is created from the four equidistant tangents on a circle, the length of the circumference of the inscribed circle can be demarcated in the perimeter of the superscribed square. It is called rectification of the circumference of the circle).

\section{Part III (Area of the arbelos)}

Let us calculate now the area of the arbelos with the known two $\pi$ values, official $\pi$ value and new one called Gayatri $\pi$ value.

\section{With official $\pi$ value}

$$
\frac{\pi}{4} \times 0.23606797749=\frac{3.14159265358}{4} \times 0.23606797749=0.18540735595
$$

(S. No. 10)

$\pi \times 0.05901699437=3.14159265358 \times 0.05901699437=0.18540735594$

(S. No. 11)

16. With Gayatri $\pi$ value

$$
\frac{\pi}{4} \times 0.23606797749=\frac{3.14644660942}{4} \times 0.23606797749=0.18569382184
$$

(S.No. 10)

$$
\pi \times 0.05901699437=3.14644660942 \times 0.05901699437=0.18569382183
$$

(S.No. 11)

17. Finally, we obtain two different values representing same area of the arbelos of Archimedes.

Official $\pi$ value gives: 0.18540735595 and

Gayatri $\pi$ value gives: 0.18569382184

Which one is the actual value for the area of the arbelos? The answer can be found in Part IV.

\section{Part IV}

18. In the Figure 1 we have Golden Ratio, HB equal to $\frac{\sqrt{5}-1}{2}=0.61803398874$

19. Let us divide area of the arbelos of S.No. 17 with the Cube of Golden Ratio $=\left(\frac{\sqrt{5}-1}{2}\right)^{3}$ and multiply it with $\frac{16}{14-\sqrt{2}}$ of the formula, derived in the S.No.14, which finally gives the area of the square $\mathrm{ABCD}$, equal to 1.

The $\pi$ value that gives the exact area of the square equal to 1 is confirmed as the real $\pi$ value. Here, the Golden Ratio decides, the real $\pi$ value, by choosing the correct area of the arbelos of Archimedes of S.No. 17 20. $\quad$ Area of the arbelos obtained with official $\pi$ value (S.No. 17)

$$
\frac{0.18540735595}{\left(\frac{\sqrt{5}-1}{2}\right)^{3}} \times \frac{16}{14-\sqrt{2}}
$$

Let us use simple calculator for the value of cube of Golden Ratio, which gives 0.23606797748

$$
\begin{aligned}
& =\frac{0.18540735595}{0.23606797748} \times \frac{16}{14-\sqrt{2}} \\
& =\frac{0.18540735595}{0.23606797748} \times 1.27127534534=0.99845732139
\end{aligned}
$$

21. Area of the arbelos obtained with Gayatri $\pi$ value (S.No. 17). Let us repeat steps of S.No. 20 here:

$$
\frac{0.18569382184}{\left(\frac{\sqrt{5}-1}{2}\right)^{3}} \times \frac{16}{14-\sqrt{2}}=\frac{0.18569382184}{0.23606797748} \times 1.27127534534=1
$$


As the exact area of the superscirbed square is obtained, it is clear, therefore, that, the real $\pi$ value is $\frac{14-\sqrt{2}}{4}$ $=3.14644660942 \ldots$

\section{Conclusion}

It is well known that there exists a simple relationship between circle and square. In the present study, it is clear such simple relation also exists between Golden Ratio and arbelos of Archimedes. This paper combines above two kinds of relations and decides the real $\pi$ value, as $\frac{14-\sqrt{2}}{4}=3.14644660942 \ldots$

\section{References}

[1]. Lennart Berggren, Jonathan Borwein, Peter Borwein (1997), Pi: A source Book, $2^{\text {nd }}$ edition, Springer-Verlag Ney York Berlin Heidelberg SPIN 10746250

[2]. Alfred S. Posamentier \& Ingmar Lehmann (2004), $\pi$, A Biography of the World's Most Mysterious Number, Prometheus Books, New York 14228-2197.

[3]. RD Sarva Jagannada Reddy (2014), New Method of Computing Pi value (Siva Method). IOSR Journal of Mathematics, e-ISSN: 2278-3008, p-ISSN: 2319-7676. Volume 10, Issue 1 Ver. IV. (Feb. 2014), PP 48-49.

[4]. RD Sarva Jagannada Reddy (2014), Jesus Method to Compute the Circumference of A Circle and Exact Pi Value. IOSR Journal of Mathematics, e-ISSN: 2278-3008, p-ISSN: 2319-7676. Volume 10, Issue 1 Ver. I. (Jan. 2014), PP 58-59.

[5]. RD Sarva Jagannada Reddy (2014), Supporting Evidences To the Exact Pi Value from the Works Of Hippocrates Of Chios, Alfred S. Posamentier And Ingmar Lehmann. IOSR Journal of Mathematics, e-ISSN: 2278-3008, p-ISSN:2319-7676. Volume 10, Issue 2 Ver. II (Mar-Apr. 2014), PP 09-12

[6]. RD Sarva Jagannada Reddy (2014), New Pi Value: Its Derivation and Demarcation of an Area of Circle Equal to Pi/4 in A Square. International Journal of Mathematics and Statistics Invention, E-ISSN: 2321 - 4767 P-ISSN: 2321 - 4759. Volume 2 Issue 5, May. 2014, PP-33-38.

[7]. RD Sarva Jagannada Reddy (2014), Pythagorean way of Proof for the segmental areas of one square with that of rectangles of adjoining square. IOSR Journal of Mathematics, e-ISSN: 2278-3008, p-ISSN:2319-7676. Volume 10, Issue 3 Ver. III (May-Jun. 2014), PP 17-20.

[8]. RD Sarva Jagannada Reddy (2014), Hippocratean Squaring Of Lunes, Semicircle and Circle. IOSR Journal of Mathematics, eISSN: 2278-3008, p-ISSN:2319-7676. Volume 10, Issue 3 Ver. II (May-Jun. 2014), PP 39-46

[9]. RD Sarva Jagannada Reddy (2014), Durga Method of Squaring A Circle. IOSR Journal of Mathematics, e-ISSN: 2278-3008, pISSN:2319-7676. Volume 10, Issue 1 Ver. IV. (Feb. 2014), PP 14-15

[10]. RD Sarva Jagannada Reddy (2014), The unsuitability of the application of Pythagorean Theorem of Exhaustion Method, in finding the actual length of the circumference of the circle and Pi. International Journal of Engineering Inventions. e-ISSN: 2278-7461, pISSN: 2319-6491, Volume 3, Issue 11 (June 2014) PP: 29-35.

[11]. RD Sarva Jagannadha Reddy (2014), Pi of the Circle, at www.rsjreddy.webnode.com.

[12]. R.D. Sarva Jagannadha Reddy (2014). Pi treatment for the constituent rectangles of the superscribed square in the study of exact area of the inscribed circle and its value of Pi (SV University Method*). IOSR Journal of Mathematics (IOSR-JM), e-ISSN: 22785728, p-ISSN: 2319-765X. Volume 10, Issue 4 Ver. I (Jul-Aug. 2014), PP 44-48. 